\title{
Influence of Farm Yard Manure on Nematode Infestation, Yield and Quality of Cucumber
}

\author{
Judith A. Odhiambo ${ }^{1 *}$ and Joseph N. Aguyoh ${ }^{2}$ \\ ${ }^{1}$ Department of Agricultural Sciences, Kisii University \\ Kisii, Kenya \\ ${ }^{2}$ Department of Agronomy and Environmental Sciences, Rongo University \\ Rongo, Kenya \\ *Corresponding author's email: otishanan [AT] yahoo.com
}

\begin{abstract}
Cucumber production in Kenya is faced with a number of challenges that include nematode infestation, low yield and quality of the crop resulting into low returns. In an effort to solve some of these challenges, a study was conducted to ascertain the effects of farmyard manure on nematode infestation, yield and quality of cucumber at Rongo University School of Agriculture Research Farm from July to October 2017 and repeated from October 2017 to January 2018. Three seeds of cucumber 'Ashley' were sown directly in 3.5-liter plastic pots containing $8 \mathrm{~kg}$ of sterilized air dried growth medium made up of sand and top soil in the ratio of 1:2 respectively. The treatments were four levels of cattle manure 0 (control), 7.5, 11.3 and 15 ton/ha. Each pot was then inoculated with 5 juvenile root knot nematodes (Meloidogyne spp). The experiment was performed under completely randomized block design with three replications. Data was collected on yield, quality and nematode population dynamics and then subjected to Analysis of Variance (ANOVA) at $P \leq 0.05$. The Number of fruits per vine, number of deformed fruits per vine, fruit weight, length, diameter, firmness and TSS were significantly affected by FYM application. FYM also affected the number of root galls and nematode population.
\end{abstract}

Keywords---- Cucumber, galling index, manure, nematode, yield

\section{INTRODUCTION}

Organic soil amendments, including compost, green manures, and lightly incorporated organic mulches, have been reported to improve crop performance and manage nematode population dynamics in the soil. Yields obtained by farmers in certain regions are often are very low especially, in intensive cropping systems due to imbalance in the use of fertilizer and continuous cropping which have led to several nutrients becoming deficient (Enujeke, 2013). The application of manures to soil provides potential benefits such as improving the fertility, structure, water holding capacity of soil, increasing soil organic matter and reducing the amount of synthetic fertilizer needed for crop production (Phan et al., 2002; Blay et al., 2002). In study by Lawal et al., (2017) application of poultry manure in combination with mineral fertilizer enhanced soil nutrient status of Ferruginous soil both in short and long term. Manures are the main sources of nitrogen $(\mathrm{N})$ supply in organic crop production. Nitrogen availability from applied manure includes the inorganic $\mathrm{N}$ (NO3-N and NH4-N) in manure plus the amount of organic $\mathrm{N}$ mineralized following application. Farmyard manure releases nutrients slowly and steadily and activates soil microbial biomass (Belay et al., 2001). Organic manures can sustain cropping systems through better nutrient recycling and improvement of soil physical attributes (El-Shakweer et al., 1998). Considerable interest has however developed in the possibility of using organic manures to reduce nematode populations and increase crop yields (Johnson, 1962).

Prior to the widespread use of commercial/inorganic fertilizers, vegetable producers relied heavily on livestock manures and crop rotations involving legumes to maintain soil fertility (Baker et al., 1998). In their study, Eifediyi and Remison (2010) reported that the fruit length, fruit girth, fruit weight per plant and fruit weight per hectare of cucumber were significantly influenced by the application of farmyard manure x fertilizer. The highest weight of $2.43 \mathrm{~kg}$ per plant and yield per hectare of $43,259 \mathrm{~kg} / \mathrm{ha}$ were obtained with $10 \mathrm{t} / \mathrm{ha}$ farmyard manure and $400 \mathrm{~kg} / \mathrm{ha}$ of fertilizer which were $166.42 \%$ higher than the control. They further reported that the combined rates of farmyard manure at $10 \mathrm{t} / \mathrm{ha} \mathrm{x} 400$ $\mathrm{kg} / \mathrm{ha}$ fertilizer increased the growth characters such as the vine length and the number of leaves. Work by Musara and Chitamba (2014) reported increase in vine length, number of branches, leaf number, both female and male flowers per main vine and total fresh yield with an increase in the amount of cattle manure applied. Cattle manure application rate of $20 \mathrm{t} \mathrm{ha}^{-1}$ gave the highest growth rate and fruit yield followed by $10 \mathrm{tha}^{-1}$ and then $5 \mathrm{t} \mathrm{ha}^{-1}$. A field experiment to test the effect of different organic manure on nematode pests on cowpea reported a significant reduction in the soil population of Meloidogyne spp., Helicotylenchus sp. and Xiphinema sp (Olabiyi et al., 2007). 


\subsection{Site of Study}

\section{MATERIALS AND METHOD}

Investigations to study the growth, yield and quality of cucumber under different farm yard manure and water levels were carried out at Rongo University, School of Agriculture Research and Teaching Field in two trials. The trial from July to October 2017 and repeated from October 2017 to January 2018. The field is located at approximately latitude $00^{\circ} 46^{\prime} 00^{\prime \prime} \mathrm{S}$, longitude $34^{\circ} 36^{\prime} 00^{\prime \prime} \mathrm{E}$ and at an elevation of $1420 \mathrm{~m}$ above sea level. The area receives mean rainfall of $1600 \mathrm{~mm}$ annually and has a mean annual temperature of $20.6^{\circ} \mathrm{C}$.

\subsection{Research Establishment}

Eight kilograms $(8 \mathrm{~kg})$ of growth medium composted of sand and top soil in the ratio of 1:2 respectively was autoclaved at $128^{\circ} \mathrm{C}$ for two hours and allowed to cool for 14 days before three 'Ashley' seeds were planted in a 3.5 litre plastic pot. After two weeks of planting, the seedlings were thinned to one seedling per pot and grown to maturity. The nematode inoculums of root knot nematode (Meloidogyne spp.) were prepared from heavily galled tomato roots. The roots were chopped and nematode eggs extracted from the galls and hatched. Five juvenile nematodes were inoculated into each pot two weeks after planting when the crop had developed good root system. The pots were then covered with black plastic mulch to exclude light and prevent water evaporation.

\subsection{Treatment Application}

Four levels of decomposed cattle manure $(0,7.5,11.3$ and 15 ton/ha that is equivalent to $0,0.018,0.027$ and 0.036 $\mathrm{kg} / \mathrm{pot}$ ) were used. All treatments were replicated three times under completely randomized block design. Nematode populations were assessed at the end of the experiment using Baermann's test. Galling index was done at the end of the experiment as described by Zeck (1971).

\subsection{Study parameters}

During the experimental period, the following were collected for analysis.

\subsubsection{Growth}

Plant vine length $(\mathrm{cm})$ was measured on weekly basis starting from the third week after emergence to the final harvest. The number of leaves on the main vine, stem diameter, number of nodes and internodes length $(\mathrm{cm})$ on each vine was also measured at the start of harvesting.

\subsubsection{Yield}

Number of fruits per vine and fruit weight (in $\mathrm{kg}$ ) per plant was recorded at the end of the harvest period.

\subsubsection{Fruit Quality}

Fruits were harvested from four plants per replicate per week and their number and weight recorded. Fruit quality in terms of fruit diameter $(\mathrm{cm})$, fruit length $(\mathrm{cm})$ and total soluble solids were measured from five randomly selected fruits from each treatment.

\subsubsection{Nematode Indexing}

At the beginning of the experiment, soil mixtures were inoculated with equal amounts of nematode and the Baermann's funnel method as described by Barkerm, et al., (1985) was used to establish the nematode populations from the samples, all plant samples were uprooted and galling index done. The rating scheme of 0-10 developed by Zeck (1971) for evaluation of root-knot nematode infection, root infection and galling was used to quantify the level of damage by nematodes as follows;

$\begin{array}{ll}0 & \text { Healthy root systems, no infection } \\ 1 & \text { Very few galls, only detected on close examination } \\ 2 & \text { Small galls, easy to detect } \\ 3 & \text { Numerous galls } \\ 4 & \text { Numerous small galls and a few big galls } \\ 5 & 25 \% \text { of the root system severely galled and not functioning } \\ 6 & 50 \% \text { of the root system severely galled and not functioning } \\ 7 & 75 \% \text { of the root system severely galled and not functioning } \\ 8 & \text { No healthy root, plant still green } \\ 9 & \text { Root rotting completely galled and plant dying } \\ 10 & \text { Plant and roots dead. }\end{array}$

\subsection{Data analysis}

All data collected were subjected to analysis of variance using SAS 9.4 at $\mathrm{P} \leq 0.05$ and significant means were separated using Duncan's multiple range tests. 


\subsection{Effect of Manure Levels on Cucumber Flowers}

\section{RESULTS}

There was no significant different on flowering between the two trials and therefore the data was averaged a cross the trials. Generally, there was earlier male flower formation a cross all treatments. The level of farm yard manure had a significant effect on the expression of both male and female flowers in cucumber (Table 1). Significantly more female flowers were observed in pots treated with different levels of farm yard manure compared to control at both 63 and 70 DAP. Contrastingly, significantly low male/female flower ratio was observed in all farm yard manure treatments compared to control during the same period of time.

Table 1: Effect of Farm Yard Manure on Cucumber Flowering

\begin{tabular}{|c|c|c|c|c|c|c|c|c|c|c|c|c|}
\hline \multirow{3}{*}{$\begin{array}{l}\text { FYM } \\
\text { (ton/ha) }\end{array}$} & \multicolumn{11}{|c|}{ Days After Planting (DAP) } & \multirow[b]{3}{*}{$\mathrm{M} / \mathrm{F}$} \\
\hline & \multicolumn{3}{|l|}{49} & \multicolumn{3}{|l|}{56} & \multicolumn{3}{|c|}{63} & \multirow{2}{*}{\multicolumn{2}{|c|}{70}} & \\
\hline & MF & FF & $\mathrm{M} / \mathrm{F}$ & MF & $\mathrm{FF}$ & $\mathrm{M} / \mathrm{F}$ & MF & FF & $\mathrm{M} / \mathrm{F}$ & & & \\
\hline $0^{\mathrm{k}}$ & 2.0 & 0 & - & 14.7 & 8.1 & 1.8 & 30.9 & $12.6 b$ & $2.4 \mathrm{a}$ & $32.5 \mathrm{ab}$ & $17.1 \mathrm{~b}$ & $1.9 \mathrm{a}$ \\
\hline 7.5 & 2.0 & 0 & - & 14.5 & 8.0 & 1.8 & 30.3 & $14.5 \mathrm{a}$ & $2.0 \mathrm{~b}$ & $33.3 \mathrm{a}$ & $18.2 \mathrm{a}$ & $1.7 \mathrm{~b}$ \\
\hline 11.3 & 2.0 & 0 & - & 14.1 & 8.2 & 1.7 & 31 & $13.5 \mathrm{ab}$ & $2.2 \mathrm{~b}$ & $32.7 \mathrm{ab}$ & $17.5 \mathrm{ab}$ & $1.7 \mathrm{~b}$ \\
\hline 15.0 & 2.0 & 0 & - & 14.9 & 7.9 & 1.9 & 31 & $14.3 \mathrm{a}$ & $2.1 \mathrm{~b}$ & $32.0 \mathrm{~b}$ & $18.2 \mathrm{a}$ & $1.7 \mathrm{~b}$ \\
\hline
\end{tabular}

${ }^{\mathrm{K}} \mathrm{MF}$ : Male flowers; FF: Female flowers; M/F: Male female ratio

Means followed by same letter or no letter, within a column are not significantly different at $\mathrm{P} \leq 0.005$

\subsection{Flowers abortions}

Generally, there was low flower abortion in the FYM treated cucumber throughout the study period for both trials with higher number of abortions in the second trial (Table 2). In trial one, a $25 \%$ significant reduction in flower abortion was observed in $15 \mathrm{ton} /$ ha FYM treated cucumber at 70 DAP compared to the other treatments which did not have any significant differences amongst them. In trial two, a significant 35\%, 21\% and 17\% reduction in flower abortion was observed in the highest level of manure application at 56, 70 and 84 DAP respectively compared to other treatments.

Table 2: Effects of Farm Yard Manure on Cucumber percent flower abortions

\begin{tabular}{|c|c|c|c|c|c|c|}
\hline \multirow{3}{*}{$\begin{array}{l}\text { FYM } \\
\text { (ton/ha) }\end{array}$} & \multicolumn{6}{|c|}{ Percent Flower Abortion } \\
\hline & Trial one & & & Trial two & & \\
\hline & $56 \mathrm{DAP}^{\mathrm{k}}$ & 70 DAP & 84 DAP & 56 DAP & 70 DAP & 84 DAP \\
\hline 0 & 5.0 & $6.0 \mathrm{a}$ & 6.2 & $5.4 \mathrm{a}$ & $8.4 \mathrm{a}$ & $9.0 \mathrm{a}$ \\
\hline 7.5 & 5.0 & $6.4 \mathrm{a}$ & 6.0 & $4.5 b$ & $7.6 \mathrm{~b}$ & $9.5 \mathrm{a}$ \\
\hline 11.3 & 4.9 & $6.0 \mathrm{a}$ & 5.7 & $3.6 \mathrm{c}$ & $6.7 \mathrm{c}$ & $8.8 \mathrm{a}$ \\
\hline 15.0 & 4.8 & $4.8 b$ & 5.8 & $3.5 \mathrm{c}$ & $6.6 \mathrm{c}$ & $7.9 \mathrm{~b}$ \\
\hline
\end{tabular}

K DAP: Days after Planting

Means followed by same letter or no letter, within a column are not significantly different at $\mathrm{P} \leq 0.005$

\subsection{Effect of Manure Levels on Cucumber Yield and Quality Components}

There was no significant difference on cucumber fruit quality and yield components between the two trials and therefore data was averaged across the two trials. A significant $16.0 \%$ increase in the number of cucumber fruits harvested was observed in treatments receiving highest FYM amendment of 15-ton ha $^{-1}$ compared to control in which no FYM was added (Table 3). The same trend was observed for fruit weight, fruit length and fruit diameter where $14 \%$ , $13 \%$ and $16 \%$ significant increase was respectively observed in fruits under the highest FYM application level compared to the treatments with no FYM application.

Table 3: Effect of Farm Yard Manure on Cucumber Fruit quality

\begin{tabular}{lllllll}
\hline FYM (tons/ha) & $\begin{array}{l}\text { Number } \\
\text { of Fruit }\end{array}$ & $\begin{array}{l}\text { Fruit weight } \\
(\mathrm{g})\end{array}$ & $\begin{array}{l}\text { Fruit length } \\
(\mathrm{cm})\end{array}$ & $\begin{array}{l}\text { Fruit } \\
\text { diameter } \\
(\mathrm{cm})\end{array}$ & Firmness & TSS \\
\hline $0^{\mathrm{k}}$ & $9.8 \mathrm{~b}$ & $148.1 \mathrm{c}$ & $14.8 \mathrm{c}$ & $3.7 \mathrm{~b}$ & $22.6 \mathrm{~b}$ & $3.1 \mathrm{~b}$ \\
7.5 & $10.6 \mathrm{ab}$ & $156.7 \mathrm{~b}$ & $15.2 \mathrm{c}$ & $3.8 \mathrm{~b}$ & $22.5 \mathrm{ab}$ & $3.0 \mathrm{a}$ \\
11.3 & $10.8 \mathrm{ab}$ & $162.3 \mathrm{a}$ & $15.9 \mathrm{~b}$ & $3.9 \mathrm{~b}$ & $22.3 \mathrm{ab}$ & $3.0 \mathrm{a}$ \\
15.0 & $11.4 \mathrm{a}$ & $168.9 \mathrm{a}$ & $16.7 \mathrm{a}$ & $4.3 \mathrm{a}$ & $22.2 \mathrm{a}$ & $3.0 \mathrm{a}$ \\
\hline
\end{tabular}

$\mathrm{K}$ TSS: Total soluble solids (Brix)

Means followed by same letter, within columns are not significantly different at $\mathrm{P} \leq 0.005$ 
The firmness of the fruits that determines the shelf life of the fruit was significantly affected by level of FYM application and decreased with increase in manure levels. The highest level of manure application resulted in a significant $10.0 \%$ reduction in the firmness of cucumber fruits.

Total soluble solids (TSS) measurements showed similar tread where $8.0 \%$ significantly low concentrations was observed among all manure levels compared to fruits planted with no FYM application.

\subsection{Effect of Manure Levels on Cucumber Root Knot Nematodes}

There were no significant differences between the two trials on and therefore data was pulled across the trials. There were significantly few galls in highest manure amendment treatment of 15 tons/ha compared to other manure treatments (Fig. 1). There was a progressive decrease in the nematode population with the increasing manure amendment levels with the highest manure amendment treatment of 15 tons/ha having significantly low nematode population compared to the control.

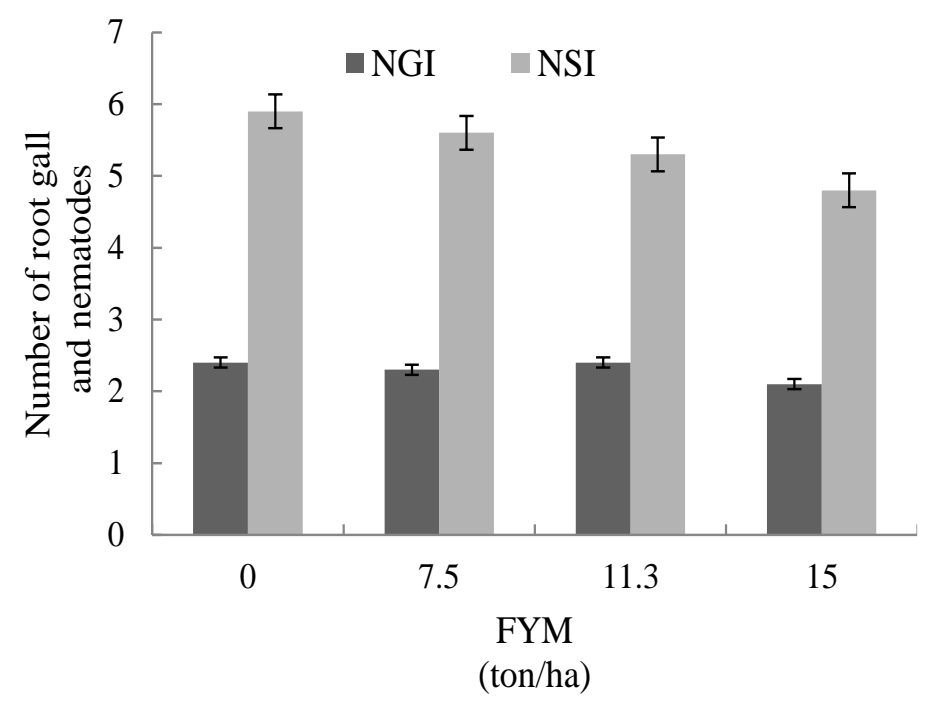

Figure 1: Effect of FYM Levels on Root-knot Nematode. NGI: Nematode gall Index; NSS: Nematode Soil Index

\section{DISCUSSION}

\subsection{Effects of Farm Yard Manure Levels on Cucumber Flowers}

Flowering is an important physiological stage in the growth of cucumber. The rate at which the plant is flowering, the days it takes from planting to the $1^{\text {st }}$ flowering and the number of male and female flower are important determinants of rate and success of pollination. Our study found out that FYM amendment increases the number of female flower formation and maintains low male/female flower ration, a condition that increases the chances of successful pollination and fertilization of all female flowers produced. This could be attributed to availability of nutrient for the growth of the plant which is essential for transitioning from vegetative to flowering/reproductive in cucumber plant

Production of male flowers occurred earlier in the growth cycle in all treatments, however with time there was exponential increase in the production of female flowers in manure amendment treatments that resulted in a reduction in the ratio of male to female flowers. This was also evidenced as manure levels increased. As the cucumber plant grew, the more photosynthetic assimilates ware available to support the female flower that was to be vital in yield attainment.

\subsection{Flowers abortion}

Once the vine had flowered the most important aspect was for the vine to maintain, the female flower into a fruit and subsequent fruit being harvested. The loss of flower and fruit during this period is very crucial and the high flower and fruit abortion in the $1^{\text {st }}$ trial explains the low yields to this trial. The low flower abortions exhibited in the high manure levels was due to availability of enough nutrients for the plant to support itself and the fruit/flowers to maturity. The abortion of fruit in the low manure levels and control in this study is therefore presumed to be as a response of limited soil nutrients resources for the new sinks. This supports Marceilis (1991) finding that first flowers and fruits exerts the greatest sink for carbohydrates therefore suppressing growth of other flowers and fruits causing their abortions. 


\subsection{Cucumber Yield}

Crop yield is always an important effective and economic index for consideration in the crop development. In fruit crops, the duration the fruits take to mature is an important attribute that determines the economic yield of such crop. In our experiment high manure levels increased the average number of fruits per vine and the average weight of cucumber in both trials. This finding is in agreement with Makinde et al., (2007) who reported an increase in melon growth and yield under organic mineral fertilizer application at 4 ton/ha.

\subsection{Cucumber Quality}

The quality of cucumber is an important aspect on the marketability of the fruits. Fruit size, shape, length and diameter are among the physical/tangible parameters' that are used to assess the quality of cucumber. From our research experiment, increased levels of FYM reduced the number of deformed fruits. Fruit development being an energy requiring process for it to grow uniformly and acquire the desired shape and size, increased FYM levels played an important role to achieve this, inadequacy of soil nutrients therefore impairs the developments of the fruit and this explains the deformation of more fruits in low manure levels and the control.

Cucumber length and diameter are other important parameters in quality. The size of the fruit will influence their marketability and this usually depends on the personal preference of the buyer. In our research experiment, high FYM levels considerably increased the length and diameter of cucumber fruits. This could be due to the availability of nutrients required for the fruit development.

\subsection{Cucumber Root Knot Nematodes}

Manure levels affected the galling on roots and the total nematode population. This was only the case of the second trial where significant differences statistically were observed. There was a general reduction in root galls of nematode population in increased manure levels. In levels with high manure levels, moderate galling was observed, this support the finding of Agu (2008) who reported moderate root galls occurred on Africa yam and bean when wine as compose manure was applied, this translated to low nematode population in the soil. Plant with fewer galls would translocate more nutrients to vegetative organs than heavily galled roots and this explains the high growth in the second trial and high yields since it had fewer gall.

Addition of farm yard manure reduced nematode root gall and nematode population and resulted in increased yields. This might be due to the fact that addition of manure to the soil increased soil nutrients stats which affected plant growth. This is to agreement with the various other researchers such as Akhtar and Mahmad (1996); Akhtar (1997) who reported increased crop growth in various economic crops. Our research also found that manure in the nematode inoculated soils resulted in reduced soil nematode populations and root galling index. This was probably attributed to the fact that manures are capable of producing antagonistic fungi that could destroy nematode pest, resulting in low soil population count and reduced galls in plants roots. This study agrees with the findings of Olabiyi et al., (2007) who reported that organic materials used in cowpea field reduced root galls on cowpea roots and the ultimate nematode population in the soil, translating to high yields.

\section{REFERENCES}

- Agu, CM, 2008. Effects of Organic Manure Types on Root-Gall Nematode Disease and African Yam Bean Yield. The Journal of American Science, 4(1):76-79,

- Akhtar, M. and Mahmood, I., 1996. Organic Amendments in Relation to Nematode Management with Particular reference to India. Integrated Post Management Reviews, 1:201-215.

- Akhtar, M, 1997. Current Options in Intergrated Management of Plant Parasitic Nematodes. Integrated Post Management Reviews, 2:187-197.

- Baker, JT, Earhart DR, Baker ML, Dainello FJ, and Haby VA, 1998. Interactions of Poultry Litter, Polyethylene Mulch, and Floating Row Covers on Triploid Watermelon, Horticultural Science, 33(5): 810 - 813.

- Barkerm, KR, Carter CC, and Sasser JN, 1985. An advanced treatise on meloidogyne Vol. II Methodology. A cooperative publication of the department of Plant Pathology and the United States Agency for International Development.

- Belay, A. Classens, AS; Wehner, FC and De Beer JM, 2001. Influence of residual manure on selected nutrient elements and microbial composition of soil under long term crop rotation. South African Journal of Plant and Soil, 18:1-6.

- Blay ET, Danquah EY, Ofosu-Anim J, Ntumy JK, 2002. Effect of poultry manure on the yield of shallot. Advances in Horticultural Science, 16:13-16. 
- Eifediyi, EK and Remison, SU. 2010. Growth and Yield of Cucumber (Cucumis sativus L.) as Influenced by Farmyard Manure and Inorganic Fertilizer. Researche, 2(4):1-6

- El-Shakweer, MH, El-Sayad A, Ewees E.A and, MS, (1998). Soil and Plant analysis as a guide for interpretation of the improvement efficiency of organic conditioners added to different soils in Egypt. Communication in Soil Science and Plant Analysis 29:2067-2088.

- Enujeke, EC. 2013. Growth and yield responses of cucumber to five different rates of poultry manure in Asaba area of Delta state. International Research Journal of Agricultural Science and Soil Science, 3(11):369-375

- Enujeke, EC. 2014. Growth and yield of cucumber as influenced by poultry manure in Asaba area of Delta State, Nigeria. Tropical agricultural research \& extension, 17(2): 61-68.

- Johnson, LF, 1962. Effect of the addition of organic amendments to soil on root-knot of tomatoes. Phytopathology, 52: $410-413$.

- Lawal A. A. 1, O.A.Dada1, A. G. Adebayo2 and A.O.Togun 2017 Performance of Cucumber (Cucumis sativus L.) on Ferruginous Soil Amended with Poultry Manure and NPK 15:15:15 Fertilizer Environtropica, $14: 75-87$

- Makinde, EA, Ayoola OT and Akande, MO, 2007. Effects of organo-mineral fertilizer application on the growth and yield of egusi melon. Australian Journal of Basic and Applied Sciences, 1:15-19.

- $\quad$ Marcelis, L.F.M. 1991. Effects of sink demand on photosynthesis in cucumber. J. Expt. Bot. 42:1387-1392.

- Musara, C, and Chitamba, J. 2014. Evaluation of cattle manure application rate on the growth rate and fruit yield of cucumber (Cucumis sativas L.). International Research Journal of Agricultural Science and Soil Science, 4(9):167-171.

- Olabiyi, TI, Akanbi, WB and Adepoju LO, 2007. Control of Certain nematode Pests with Different Organic Manure on Cowpea. American-Eurasian Journal of Agricultural. \& Environmental Sciences, 2 (5): 523-527.

- Phan TC, Roel M, Cong SS, Nguyen Q, (2002) Beneficial effects of organic amendment on improving phosphorus availability and decreasing aluminum toxicity in two upland soils. Symposium no. 13 paper no. 1226 17th, W.C.SS 14-

- 21 , Thailand.

- Zeck, WM, 1971. A rating scheme for field evaluation of root knot nematodes infestation. Pflnzenschutz Nachrichten Bayer 24:141-144. 